\title{
BMJ Open Development of strategies to support home-based exercise adherence after stroke: a Delphi consensus
}

\author{
Amreen Mahmood (D) , 1,2,3 Anagha Deshmukh, ${ }^{4}$ Manikandan Natarajan, ${ }^{1,3}$ \\ Dianne Marsden, ${ }^{5,6,7}$ Glade Vyslysel, ${ }^{8}$ Sebastian Padickaparambil, ${ }^{4}$ Shwetha TS, ${ }^{4}$ \\ Artur Direito, ${ }^{9,10}$ Senthil Kumaran, ${ }^{1,3}$ Girish N, ${ }^{1}$ Harpreet Sachdev, ${ }^{11}$ \\ Sundar Kumar Veluswamy, ${ }^{12}$ Suruliraj Karthikbabu, ${ }^{13}$ B Unnikrishnan, ${ }^{14}$ \\ Coralie English (D) , ${ }^{6,15}$ John M Solomon ${ }^{1,3}$
}

To cite: Mahmood A,

Deshmukh A, Natarajan M, et al. Development of strategies to support home-based exercise adherence after stroke: a Delphi consensus. BMJ Open 2022;12:e055946. doi:10.1136/ bmjopen-2021-055946

- Prepublication history and additional supplemental material for this paper are available online. To view these files, please visit the journal online (http://dx.doi.org/10.1136/ bmjopen-2021-055946).

Society of Indian

Physiotherapists Conference 2018

Received 30 July 2021 Accepted 10 December 2021

Check for updates

(C) Author(s) (or their employer(s)) 2022. Re-use permitted under CC BY-NC. No commercial re-use. See rights and permissions. Published by BMJ.

For numbered affiliations see end of article.

Correspondence to Dr John M Solomon; john.solomon@manipal.edu

\section{ABSTRACT}

Objective To develop a set of strategies to enhance adherence to home-based exercises after stroke, and an overarching framework to classify these strategies. Method We conducted a four-round Delphi consensus (two online surveys, followed by a focus group then a consensus round). The Delphi panel consisted of 13 experts from physiotherapy, occupational therapy, clinical psychology, behaviour science and community medicine. The experts were from India, Australia and UK.

Results In round 1, a 10-item survey using openended questions was emailed to panel members and 75 strategies were generated. Of these, 25 strategies were included in round 2 for further consideration. A total of 64 strategies were finally included in the subsequent rounds. In round 3 , the strategies were categorised into nine domains-(1) patient education on stroke and recovery, (2) method of exercise prescription, (3) feedback and supervision, (4) cognitive remediation, (5) involvement of family members, (6) involvement of society, (7) promoting self-efficacy, (8) motivational strategies and (9) reminder strategies. The consensus from 12 experts (93\%) led to the development of the framework in round 4.

Conclusion We developed a framework of comprehensive strategies to assist clinicians in supporting exercise adherence among stroke survivors. It provides practical methods that can be deployed in both research and clinical practices. Future studies should explore stakeholders' experiences and the cost-effectiveness of implementing these strategies.

\section{INTRODUCTION}

Stroke is one of the leading causes of death and disability across the world. ${ }^{1}$ Rehabilitation is recommended to promote recovery, enhance independence and improve quality of life after a stroke. ${ }^{23}$ However, healthcare services and comprehensive stroke rehabilitation centres are often expensive and beyond people's reach. ${ }^{45}$ Considering the limited access to hospital-based healthcare services after stroke, ${ }^{4}$ home-based rehabilitation is often preferred and sometimes the
Strengths and limitations of this study

- The multidisciplinary expert panel consisted of specialists in exercise prescription, behavioural science and community medicine, each having diverse experiences that contributed to the development of this multi-faceted framework of strategies.

- We developed strategies specific to low-income and middle-income countries that are affordable and provide practical methods of implementation.

- One of the limitations of this study was that the individuals with stroke and their caregivers were not included in the Delphi panel.

- There was an unequal representation of experts from different specialities.

only option for stroke survivors living in lowresource settings. ${ }^{6} 7$ Home-based rehabilitation has been shown to have functional and cost benefits. ${ }^{89}$ Adherence to the home-based regimen is of utmost importance for any intervention to be beneficial. ${ }^{10}{ }^{11}$ Improving adherence to exercise programmes after stroke has been shown to improve functional recovery. ${ }^{12}$

Non-adherence to physical exercises is a common problem among stroke survivors. ${ }^{13}$ The level of adherence to prescribed homebased exercises among Indian stroke survivors was found to be only $28 \% .^{14}$ Barriers to exercise after stroke include factors at the individual, interpersonal, organisational and community levels. ${ }^{15}$ Modifiable factors include lack of knowledge about stroke, lack of supervision and motivation, and inadequate exercise prescription by healthcare providers. ${ }^{15-17}$ Other factors that impact adherence include pain, fear of falls and poststroke fatigue. ${ }^{18} 19$ In addition, environmental factors such as cost, accessibility and transport are other barriers for people with chronic 
stroke. Thus, developing effective strategies that reinforce adherence to home-based exercises is important. ${ }^{19}$ As stated by the WHO, 'increasing the effectiveness of adherence interventions may have a far greater impact on the health of the population than any improvement in specific medical treatments. ${ }^{20}$ Therefore, improving adherence to post-stroke rehabilitation may enhance recovery and improve the quality of life among stroke survivors. ${ }^{21}$

Exercise adherence can be improved through motivational interventions, behavioural change strategies, multimedia, follow-up sessions, feedback, cognitivebehavioural therapy, skill training, self-monitoring, goal setting, coping strategies and coaching. ${ }^{21-23}$ However, there is limited information on how to practically incorporate these into clinical practice. Therefore, developing strategies for promoting post-stroke exercise adherence is essential. ${ }^{12}{ }^{24}$ Identifying barriers affecting adherence to exercise, and developing strategies that can be practically implemented by stroke survivors to modify those barriers, increases the potential for improving exercise adherence. ${ }^{25}$ Thus, we aimed to develop a set of strategies to facilitate adherence to home-based exercises after stroke and a comprehensive framework to classify these strategies.

\section{METHODS}

This study was a part of a doctoral thesis that was conducted in four phases. In the first phase, we measured the level of exercise adherence among community-living stroke survivors. In the second phase, we conducted qualitative interviews with stroke survivors to understand the factors affecting exercise adherence. Using the themes derived in the second phase, a Delphi study was conducted in the third phase to develop a framework of strategies to support adherence to the home exercise programme. The fourth phase involved testing the effectiveness of the developed framework of strategies in a pilot randomised controlled trial. The methods and findings of phases I, II and IV are published elsewhere. ${ }^{141526}$ The current study (Delphi consensus) describes the process and findings of the third phase of the project.

\section{Participant recruitment}

Participants (experts) were recruited using purposive sampling. The criteria for selection were: (1) expertise in stroke/ behavioural change/community health, (2) having more than 10 years of clinical experience, (3) published in peer-reviewed journals, (4) involvement in translational and collaborative health research, and (5) employed in academia, research or clinical practice.

We identified the experts through the collaborative network of the Centre for Comprehensive Stroke Rehabilitation and Research at the Manipal Academy of Higher Education. We aimed to recruit a majority of experts from India to ensure suggestions were contextspecific to low-income and middle-income countries. We invited experts to participate in the study from different fields (physiotherapy, occupational therapy, neurology, clinical psychology, community medicine and behaviour science) to ensure that the strategies were comprehensive and covered multiple aspects of adherence.

Experts were invited via email. Those who agreed to participate gave their written consent and were included in the study. We conducted a four-round Delphi consensus; two online surveys, followed by a focus group to build a set of adherence strategies for home-based exercises based on survey results, then a final online consensus round. ${ }^{27}$ Each round took 2 months. Experts were sent two reminder emails and any non-respondents were excluded from that round. Except for the focus group, the experts were blinded to each other for all rounds, and responses were anonymous. The Delphi rounds were conducted between January 2018 and December 2018. The primary investigator, an experienced stroke physiotherapist (AM) collected and analysed the data. The focus group was conducted by another investigator (JMS) who has more than 15 years of experience in neurological rehabilitation and qualitative studies.

\section{Data collection and analysis}

Round 1

Our previous study explored factors influencing adherence to home-based exercises among stroke survivors through in-depth interviews. ${ }^{15}$ Using this information, we categorised the barriers reported by the stroke survivors into internal and external factors using the Intervention Mapping approach. ${ }^{25}$ We also performed a literature search in PubMed, Scopus, Web of Science and Cochrane using the search terms "physical exercises," "adherence," "compliance," "behavior change," and "health behavior." We reviewed studies from the bibliographies of the relevant articles. We identified health behavioural change theories and existing strategies/interventions used for improving adherence to long-term therapies. Our review of the literature identified common principles for supporting adherence such as motivation, self-efficacy, social support, the role of family, online health support (mHealth) and behavioural change techniques. ${ }^{27-34}$ Our findings from the literature and our qualitative study were combined to form a 10-item survey using openended questions in SurveyMonkey software (https:// www.surveymonkey.com/). The survey was then emailed to the expert panel (online supplemental file 1).

We merged the experts' written responses to perform content analysis ${ }^{35}$ and coded the responses using ATLAS. ti V.8 software. The responses that were suggested by more than nine out of $13(70 \%)$ experts were considered as 'certain strategies'. Responses that were not common and suggested by less than nine experts were labelled 'uncertain strategies' for further consideration in round 2.

\section{Round 2}

The second survey, consisting of only the 'uncertain strategies', was emailed to the expert panel, and they 


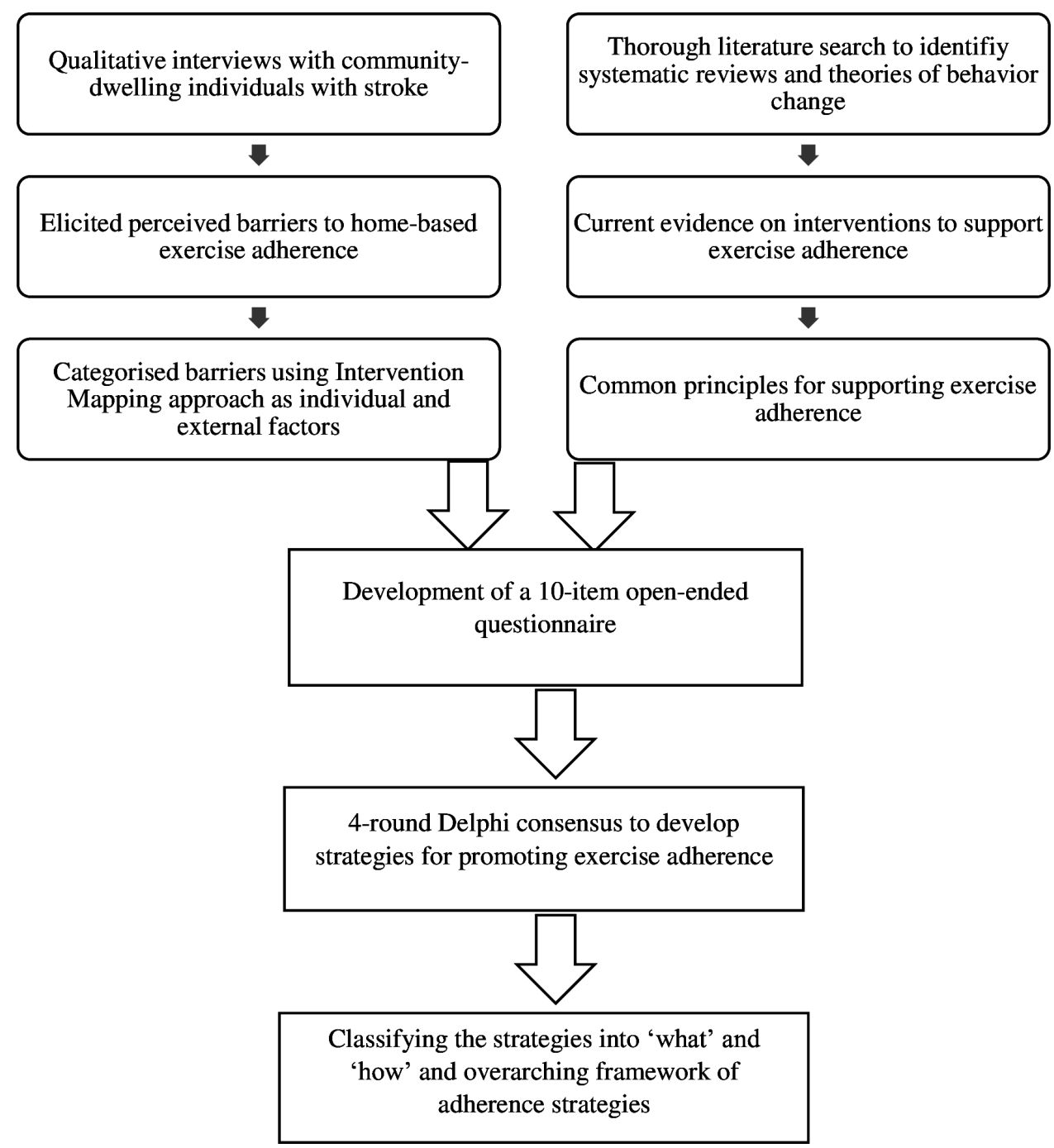

Figure 1 Process of development of adherence framework.

were asked to agree/disagree on the given strategies and provide reasons for their opinion. For an 'uncertain strategy' to become a 'certain strategy', it needed to have a majority agreement, that is, 6 out of 11 experts. This process resulted in a final set of 64 strategies.

\section{Round 3}

We then conducted a face-to-face focus group to collate the included strategies into broader categories. The expert panel was asked to categorise the list of strategies into a specific domain. They also suggested practical ways of implementing the suggested strategies such as: who should design it, the content, how it should be delivered and target stakeholders. Any experts who could not be present at the focus group were emailed the categories and asked to evaluate the draft framework.

\section{Round 4}

The framework of strategies was sent to all the experts for minor modifications and approval. The consensus from the experts led to the development of the final framework. Figure 1 shows the development of the framework.

\section{Patient and public involvement}

While this Delphi study was conducted among subject experts; opinions of patients and caregivers were used to develop the open-ended questions included in the first round of the Delphi process. Qualitative interviews were conducted among community-dwelling stroke survivors to explore their exercise behaviour and barriers to exercise adherence in the second phase of this project. The patients' opinions highlighted that not only patientrelated factors, but family, healthcare system and community-level factors played a role in exercise nonadherence. This information was used in the development of open-ended questions that were included in the first round of the Delphi process. Therefore, the patients' perceptions and needs were incorporated in this study for designing adherence strategies and framework.

\section{RESULTS}

We invited 22 experts across India and abroad to participate in the Delphi survey. Thirteen consented 


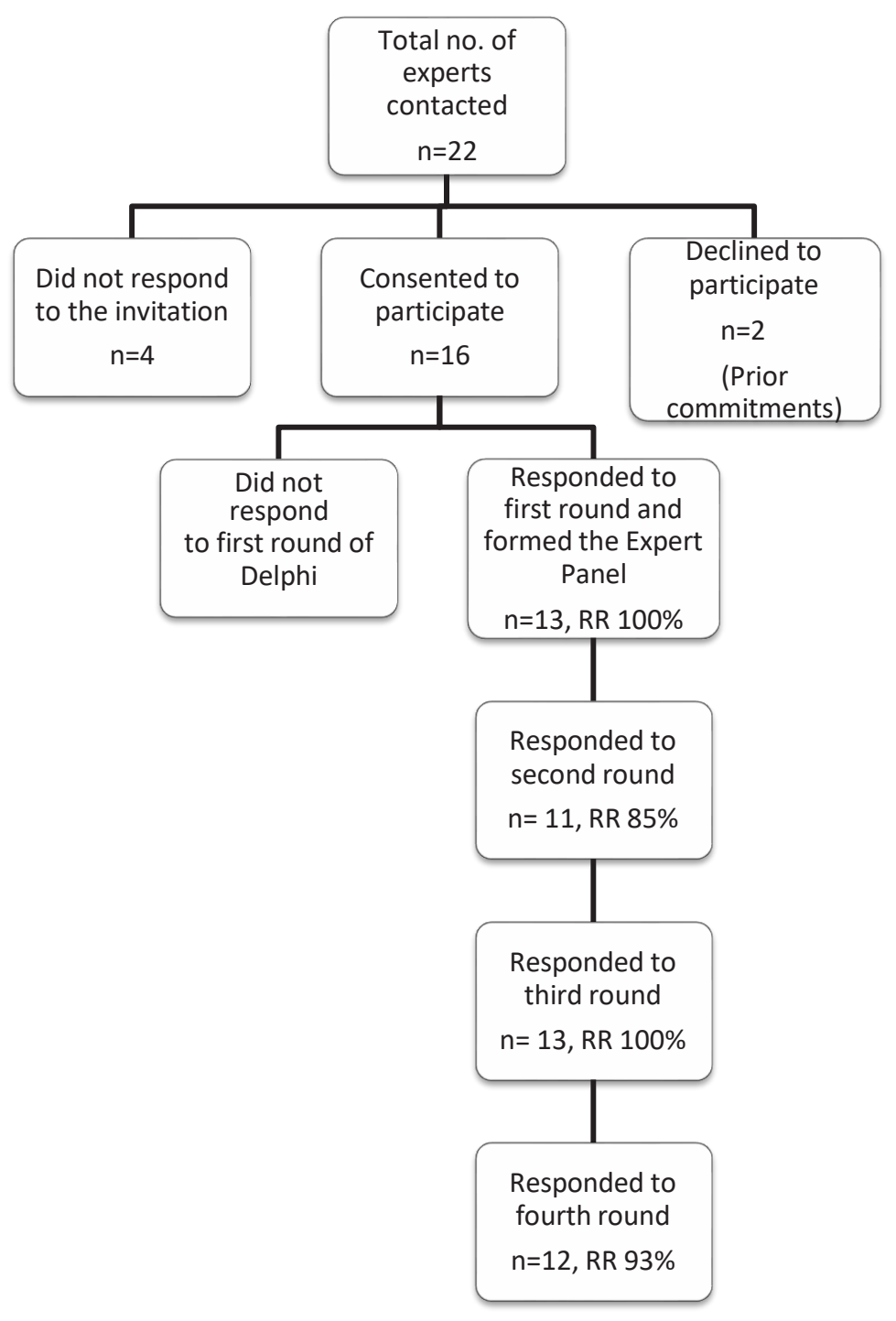

\section{RR: Response rate}

Figure 2 Flow of participants and response rate in each round.

to participate in the study and responded to round 1 (figure 2). The final panel consisted of physiotherapists $(n=7)$, clinical psychologists $(n=3)$, occupational therapist $(n=1)$, behaviour scientist $(n=1)$ and epidemiologist $(n=1)$. Three experts were from Australia, one from the UK, and the remaining experts were from India. Each panel member had more than 10 years of clinical experience and multiple publications (table 1).

\section{Round 1}

The open-ended survey and the summary of responses received in the first round are provided in online supplemental file 1 . The content analysis of the responses received in round one yielded a total of 75 strategies. Of these, 50 strategies were suggested by more than nine experts (ie, $>70 \%)$ and were considered 'certain'. The remaining 25 were considered 'uncertain' strategies (suggested by less than nine experts) and were included in the next round for further consideration.

\section{Round 2}

The response rate for round two was $85 \%$ (11 experts.) More than $60 \%$ of experts agreed on 14 out of 25 uncertain strategies and hence those were included. The remaining 11 strategies with less than $60 \%$ agreement were excluded. The percentage of agreement for each uncertain strategy is provided in online supplemental file 2 . We included a total of 64 strategies $(50+14)$ for the subsequent rounds.

\section{Round 3}

Six experts (three clinical psychologists, two physiotherapists and one epidemiologist) participated in the face-toface focus group. The remaining seven experts responded 


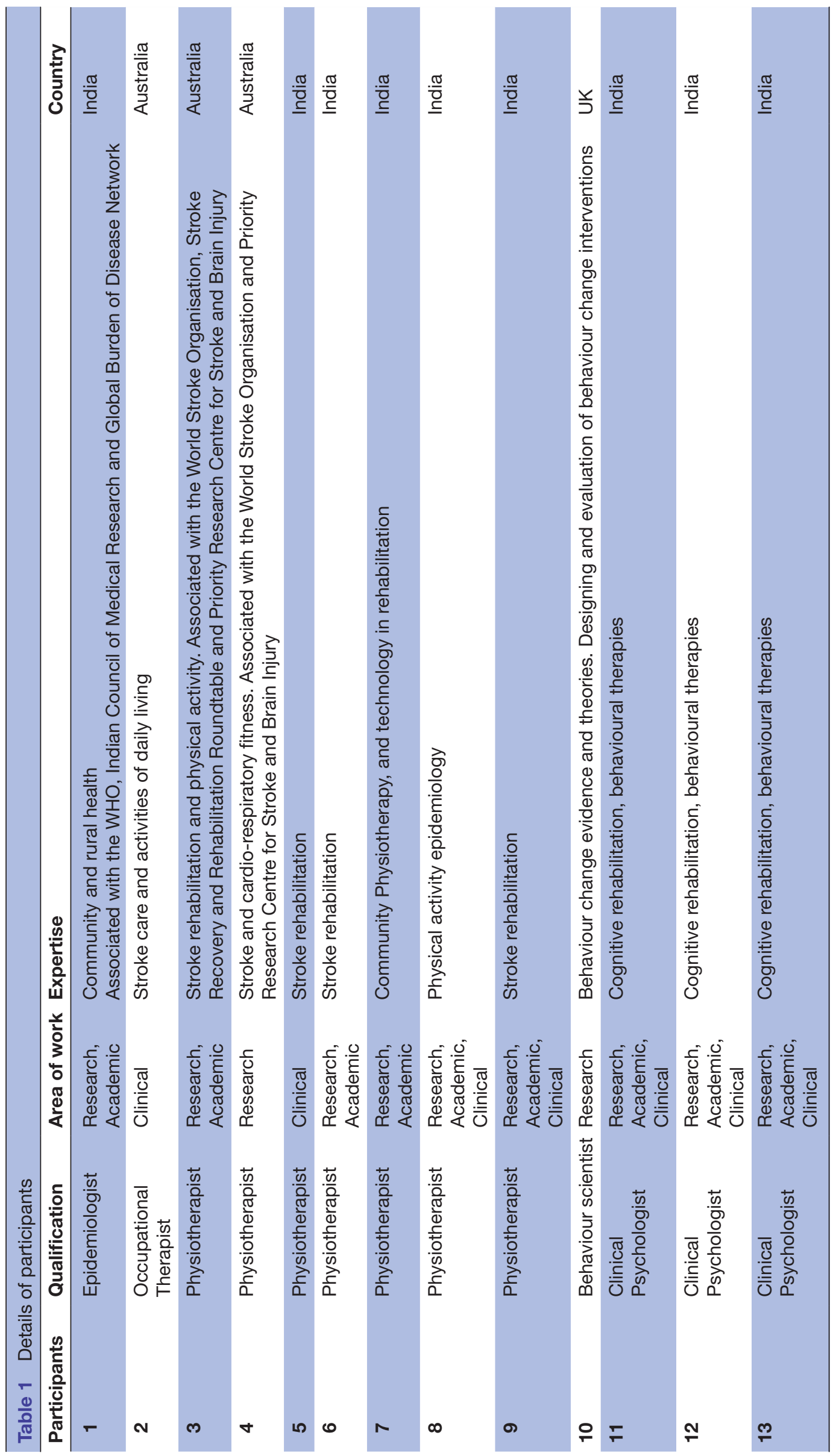


via email and provided input to the framework. The final 64 strategies were grouped into nine domains (table 2).

\section{Round 4}

The final framework of strategies for improving homebased exercise adherence was agreed on by $12(93 \%$ response rate) experts. The experts agreed that the exercise-related strategies should be designed and delivered by therapists having experience in stroke care such as an occupational therapist, physiotherapist, physiatrist or stroke nurse. They suggested that the strategies requiring behavioural techniques should be designed and supervised by a licensed clinical psychologist or behaviour therapist. In the following section, we have highlighted the key suggestions from the expert committee under each domain. The details of the framework are provided in online supplemental file 3 .

Strategies for improving adherence to home-based exercises post stroke under each domain

\section{Domain I: patient education on stroke and recovery}

Experts agreed that the patient education should comprise of: (1) usual time course and speed of recovery, (2) the impact of practice and exercise on recovery, (3) adverse effects of rest and positive effects of activity, (4) the importance of secondary risk factor management, (5) managing complications (e.g., spasticity, pain, fatigue, contracture, depression), (6) complementary medicine (including traditional medicines and religious practices), (7) importance of adhering to the exercise programme, dosage of the exercise programme, (8) role of a caregiver, (9) recovery and return (interaction between severity and prognosis), (10) proper positioning techniques and (11) misconceptions about stroke recovery.

Methods recommended for delivering education included: written information, individual discussions, and phone calls that are individually tailored to each patient's needs, as well as conducting group sessions wherein testimonials from recovered patients and their caregivers are presented.

\section{Domain II: methods of exercise prescription}

Exercises that are prescribed should be task-specific and individually tailored based on each persons' impairments, goals and context. These exercises should be reinforced using demonstration and practice. Exercise prescription should include personalised information or messages of personal encouragement.

Additional ways for prescribing exercises may include written or pictorial instructions, videos of exercises, voiceassisted programme or internet-based applications. Other ways that can support adherence are video recording of patients' exercise performance, splitting the exercise into smaller steps for severe impairments and gradually increasing difficulty level. Gaming or gamification may also facilitate exercise adherence since it gives a sense of achievement and reinforces exercise behaviour.
Domain III: feedback and supervision

For regular feedback and supervision, maintaining an exercise $\log$, everyday activity status or updates that are monitored by the medical team could be useful for supporting adherence.

Having therapists clear any doubt that patients might have about their exercise prescription, routinely ask patients about their progress and periodically ask patients to give feedback about the quality of their interaction with therapists will provide a sense of supervision and accountability, thus facilitating adherence.

There should be regular contact with the therapists (in person or via telehealth.) Therapists can use recorded audio/video clips, individual or group discussions for feedback and supervision. Therapists should use standardised assessments to measure clinical outcomes and provide feedback on progress.

\section{Domain IV: cognitive remediation}

The experts in behavioural science and cognitive rehabilitation agreed on prescribing tasks that are focused on functional recovery, planning the exercise centred on individual goals and understanding the patient's motivation before the treatment session. Motivational interviewing or motivation enhancement therapy could be used to understand their baseline motivational level and establish intrinsic motivation for behavioural change. Providing positive feedback and reinforcement for small improvements engenders confidence in patients. Additionally, having a contingency plan for days when exercises could not be performed would prevent abrupt cessation of the exercise routine. Using behavioural activation (a treatment technique used in clinical psychology for managing depression) so that patients perform one enjoyable activity each day would keep them motivated to stick to their exercise schedule.

\section{Domain V: involvement of the family members}

Experts suggested that the family should be involved; however, the amount of assistance provided by the family needs to be balanced so as not to promote dependency. Assessing knowledge and understanding of the caregivers on post stroke exercises is crucial for them to reinforce patients' adherence. Family can be involved by being the patient's exercise partners, or by setting up exercise reminders, or by helping track the patient's progress. Demonstrating and practising exercises with family can also enhance the self-efficacy and confidence of caregivers.

Managing the expressed emotions of the family members is important as it may hinder treatment and restrict the patient's autonomy. Rotating family members in the supervision of the patient's activities can help in reducing burnout and maintaining novelty in routine.

\section{Domain VI: involvement of society/ community}

Family and friends can interact with the patient on topics not concerning the illness (areas of interest to the patient 
Table 2 Grouping of strategies into specific domains

\begin{tabular}{|c|c|c|}
\hline Items & Domains & Strategies \\
\hline 1 & $\begin{array}{l}\text { Patient education on stroke and } \\
\text { recovery }\end{array}$ & $\begin{array}{l}\text { Patient education about stroke and its treatment } \\
\text { Patient education on adherence } \\
\text { Caregiver education and involvement } \\
\text { Written instructions and pictures } \\
\text { Testimonials from recovered patients } \\
\text { Information on support agencies } \\
\text { Benefits of exercise } \\
\text { Psycho-education }\end{array}$ \\
\hline 3 & Feedback and supervision & $\begin{array}{l}\text { mHealth applications } \\
\text { Activity log } \\
\text { Feedback from patients } \\
\text { Feedback on their progress } \\
\text { Exercise charts with video/audiorecording } \\
\text { Asking to tell approach } \\
\text { Clearing doubts by the medical team } \\
\text { Regular contact with therapists } \\
\text { Recording exercises for feedback } \\
\text { Regular monitoring } \\
\text { Understand previous exposure with exercises }\end{array}$ \\
\hline 4 & Cognitive remediation & $\begin{array}{l}\text { Educating on the benefits of exercise } \\
\text { Motivational interviewing } \\
\text { Cognitive-behavioural therapy techniques } \\
\text { Behavioural activation } \\
\text { Contingency charts } \\
\text { Involving group sessions } \\
\text { Meaningful tasks } \\
\text { Psycho-education }\end{array}$ \\
\hline 6 & Involvement of society & $\begin{array}{l}\text { Involvement of friends } \\
\text { Involving group sessions } \\
\text { Modelling behaviour } \\
\text { Support and exercise groups } \\
\text { Social comparison }\end{array}$ \\
\hline 7 & Promoting self-efficacy & $\begin{array}{l}\text { Personal graph charts } \\
\text { Reduce the no of alternatives presented to the patient } \\
\text { Provide activities that can be done independently } \\
\text { Standardised assessment } \\
\text { Goal setting } \\
\text { Self-efficacy enhancement: using substitution and optimisation principles } \\
\text { Ongoing support } \\
\text { Methods of tracking exercises } \\
\text { Coaching methodology } \\
\text { Psycho-education }\end{array}$ \\
\hline
\end{tabular}




\begin{tabular}{lll} 
Table 2 Continued & Domains \\
\hline Items & Motivational strategies & Patient's videos to show improvement \\
mHealth (any form of monitoring, consultation, assessment, or therapy \\
delivered using mobile devices) \\
Interim assessments
\end{tabular}

such as work/politics/current affairs/sports.) Some strategies for involving society include having weekly phone/ face-to-face interactions with colleagues, family, and friends, or joining/creating support groups or associations of families with stroke. Testimonials of recovered patients and their experiences with rehabilitation can be used for motivating other patients. Additional ways to include community are awareness programmes for healthy adults, local group exercise for people with stroke and peer support or exercise buddies.

\section{Domain VII: promoting self-efficacy}

Experts suggested using evidence-based behaviour change strategies (e.g., the Capacity Opportunity MotivationBehaviour model ${ }^{36}$ or Intervention Mapping approach ${ }^{25}$ and using rehabilitation principles of substitution and optimisation. Some suggested strategies to promote selfefficacy include:

- Collaborating with patients to devise the best monitoring strategy for them such as exercise practice sheets, paper, electronic diary or internet-based applications.

- Providing continual support after the termination of the formal therapy programme.

- Providing personal graph charts of success that can be generated weekly or monthly.

- Ensuring an adequate number of activities in which the patient can engage independently or with minimal supervision.

- Identifying anchors in the day (sleep times/meals/ activities-exercise, recreation, social) and setting a general intention of sticking to their exercise programme or developing contingency 'if/then' plans.

- Discuss and explore potential barriers that would impede or hinder exercise sessions with patients.
- Overcome barriers using pie charts, pros versus cons analysis/identification of cognitive distortions/downward arrow techniques/developing a life brochure/ movement or art-based therapeutic activities.

- Motivation interviewing to help to elicit patients' intention to adhere to exercises and understand their motivation level.

\section{Domain VIII: motivational strategies}

Panel experts suggested that motivation can be facilitated by establishing positive feedback mechanisms at home with caregivers' help to reward adherence. Motivational strategies can be implemented as follows:

- Showing functional improvements or devising individual graphs (every three sessions plus monthly).

- Having a display board/wall of fame where "patient of the month' and photos of patients achieving good outcomes could be displayed in a rehabilitation centre or common mHealth application.

- Using productivity monitoring tools to keep them motivated.

- Maintaining a daily log for positive feelings or gratitude journal, and telephone follow-up where the medical team provides words of encouragement can promote adherence.

- Having video feedback at regular intervals, setting progressive but attainable targets, and involving patients in goal setting may motivate patients to continue exercising.

- Devising wrist bands of different colours (coded for level of recovery and mastery of tasks).

- Giving t-shirts or wrist bands of that colour and upgrading as they progress to encourage regular exercising.

- Competitions during group sessions among people with similar impairments and provide tokens or badges 
for improvement that can be exchanged for tangible rewards to make exercising fun and interesting.

- Having an interactive internet-based community where people can add friends to motivate each other to exercise can also be a solution in times of social distancing.

\section{Domain IX: reminder strategies}

Experts agreed on reminder strategies including:

- Calling patients regularly and visiting them weekly or fortnightly.

- Using sticky notes in the patients' homes, tally sheets, pamphlets or text messages/WhatsApp reminders.

- Therapists can show exercise videos so that patients can accurately remember each exercise step and use the same video for home practice.

- Use of technology such as sending small feedback surveys, disease information, scientific literature, and progress cards to keep the patients engaged and motivated to continue exercises.

- Using daily logs (electronic or paper-and-pencil) and weekly reviewing of the exercise log to help stick to a schedule.

\section{DISCUSSION}

We aimed to develop a comprehensive set of clinically applicable strategies for optimising adherence to homebased exercises after a stroke. In a Delphi method, experts from different fields co-construct knowledge and provide recommendations on a particular topic. ${ }^{37}$ In our study, we incorporated knowledge from experts in exercise science, behaviour science and experts experienced in community care to develop the set of strategies.

The 10-item open-ended survey, used in the first round, was based on our qualitative study ${ }^{15}$ that explored factors influencing adherence among stroke survivors using the Intervention Mapping approach, ${ }^{38}$ which is underpinned by the Socio-Ecological Model. ${ }^{39}$ Our framework is constructed on the Socio-Ecological Model of behavioural change. Since there is limited access to healthcare facilities, higher cost of clinic-based rehabilitation, and lack of transport to hospital setup in low resource settings, homebased exercise adherence becomes crucial for recovery. The developed adherence strategies could be influential for the success of home-based rehabilitation in the long term.

The suggested strategies were categorised into nine domains, which were in line with the findings in existing systematic reviews. ${ }^{21} 4041$ The included studies reported behaviour strategies and theories such as self-efficacy, ${ }^{21}$ motivational interventions, ${ }^{40}$ social-cognitive theory, ${ }^{32}$ activity-monitoring, feedback system, goal-setting, ${ }^{41}$ selfregulated exercises, ${ }^{42}$ for improving adherence. However, none of the studies had used Delphi approaches and provided broad concepts for enhancing exercise adherence without providing specific context, culture or techniques for delivering the interventions.
Adherence is affected by multiple factors such as age, self-efficacy, caregiver support, previous exercise behaviour, the severity of stroke and stages of stroke recovery. ${ }^{18-20} 4344$ Therefore, the framework of strategies provides the opportunity to individualise the strategies based on each person's impairments, recovery, the severity of stroke and available support system. The exercises can be tailored depending on the abilities and context of each person.

Adherence to poststroke rehabilitation is a dynamic process and changes with each stage of recovery, characterised by a higher adherence rate during the initial period of recovery, followed by a slow decrease in adherence rate and a stable phase where adherence does not change much. ${ }^{45}$ Some strategies such as enhancing self-efficacy, activity scheduling, regular feedback and monitoring can be initiated during the early phase while strategies such as interim progress tracking, personal graphs, involvement of peer group, gamification of exercises, providing rewards, and reminders can be started gradually to break the monotony of ongoing exercise programmes and encourage adherence. Therefore, implementing these adherence strategies early in rehabilitation can be beneficial for maintaining adherent behaviour in the long term. The results from a metaanalysis of mixed disease populations demonstrated that adherence is low when perceived disease severity is high among patients with serious illnesses. ${ }^{46}$ However, future studies are needed to establish the effects of stroke severity on exercise adherence.

The different sets of strategies within the framework can be deployed to improve exercise adherence after stroke. The framework is useful for stroke survivors, caregivers and healthcare providers as it offers adherence techniques at a personal, interpersonal and organisational level. It gives clear recommendations on each strategy's content, different ways of delivering it, healthcare professionals who should design it, and one who might benefit from those strategies.

The strategies that were agreed on by more than $60 \%$ of experts were included while the remaining uncertain strategies were excluded. The excluded strategies were participating in social events, regular checks by neighbours or games/competition with family/caregivers. Such strategies may improve the social interaction but may not be feasible due to the caregiver's burden after stroke, ${ }^{47}$ and family members may not find adequate time for such activities. Other uncertain strategies such as virtual reality, circuit training or award function were excluded due to the cost, training and equipment required. ${ }^{15}$ Strategies such as educating patients on the location and types of stroke and educational movies were considered redundant for improving exercise adherence. ${ }^{48}$ Although social media such as Whatsapp was agreed on by the experts as a mode of reminder, Whatsapp groups were not preferred as a strategy due to fear of dissemination of inaccurate information among the participants and compromising the privacy of health information. 
The key strength of this study lies in the multidisciplinary nature of the expert panel that was recruited, which included specialists in exercise prescription, experts in behaviour and community experts having diverse experiences that contributed to developing a multi-faceted framework of strategies. Due to the pandemic that has compromised clinic-based rehabilitation worldwide, these strategies can be delivered in any healthcare setting, are easy to implement, affordable and offer a comprehensive set of strategies to facilitate exercise adherence. We have tested the framework of strategies in a recent randomised controlled trial and found it to be effective in improving adherence levels among people with stroke. ${ }^{26}$ Choosing the strategies from the framework can help in the pragmatic implementation in clinical practice or research trials. The framework is a useful guide for both clinicians and researchers to select appropriate strategies for enhancing exercise adherence.

We did not include stroke survivors and caregivers in the Delphi panel which we consider a limitation of this study. However, the perceptions of stroke survivors were explored to develop the questionnaire for the first round. ${ }^{15}$ The representation of experts from each speciality was unequal which could have influenced the decision-making process that differentiated certain vs uncertain strategies. Hence, some of the strategies deemed uncertain may have clinical relevance for supporting adherence. Moreover, as the open-ended questionnaire was developed from the literature review and opinions of stroke survivors in the previous study, the experts did not get a chance to develop the initial themes.

\section{CONCLUSION}

A set of strategies and a framework for enhancing adherence to home-based exercises after stroke has been developed and classified under nine domains: patient education on stroke and recovery, exercise prescription, feedback and supervision, cognitive remediation, the involvement of family members, the involvement of society, promoting self-efficacy, motivational strategies and reminder strategies. In countries where home-based exercises are the mainstay of rehabilitation, these strategies could reinforce self-management and facilitate adherence in the long term. Future studies should explore the experiences of stakeholders in implementing these strategies using qualitative methods. The set of strategies could be incorporated in a telerehabilitation model and cost analysis could be performed in the future.

\footnotetext{
Author affiliations

${ }^{1}$ Physiotherapy, Manipal College of Health Professions, Manipal Academy of Higher Education, Manipal, India

${ }^{2}$ Physiotherapy, Kasturba Medical College, Mangalore, Manipal Academy of Higher Education, Manipal, India

${ }^{3}$ Center for Comprehensive Stroke Rehabilitation and Research, Manipal Academy of Higher Education, Manipal, India

${ }^{4}$ Clinical Psychology, Manipal College of Health Professions, Manipal Academy of Higher Education, Manipal, India
}

${ }^{5}$ Hunter Stroke Service, Hunter New England Local Health District, New Lambton, New South Wales, Australia

${ }^{6}$ Priority Research Centre Stroke and Brain Injury, University of Newcastle, Callaghan, NSW, Australia

${ }^{7}$ Brain and Mental Health Program, Hunter Medical Research Institute, New Lambton Heights, NSW, Australia

${ }^{8}$ Westlakes Community Rehabilitation Team, Hunter New England Local Health District, Toronto, NSW, Australia

${ }^{9}$ Centre for Behaviour Change, University College London, London, UK

${ }^{10}$ Yong Loo Lin School of Medicine, National University of Singapore, Singapore

${ }^{11}$ Neurology, All India Institute of Medical Sciences, New Delhi, India

${ }^{12}$ Physiotherapy, MS Ramaiah Medical College, Bangalore, Karnataka, India

${ }^{13}$ Physiotherapy, Manipal College of Health Professions, Manipal Academy of Higher Education, Bangalore, Karnataka, India

${ }^{14}$ Community Medicine, Kasturba Medical College, Mangalore, Manipal Academy of Higher Education, Manipal, Karnataka, India

${ }^{15}$ School of Health Sciences, University of Newcastle, Newcastle, New South Wales, Australia

Twitter Amreen Mahmood @Amreen.Mahmood, Senthil Kumaran @ KumaranDSenthil and Coralie English @Coralie_English

Acknowledgements We are grateful to Dr. Margaret Galloway, University of Newcastle, Australia for her timely inputs in the language of manuscript. We thank Mr. Amit Manohar Sinha, LIC, India and Dr. Pradeepa Nayak, Manipal Academy of Higher Education, for their assistance and support during the study.

Contributors The idea was conceptualised by JMS and MN. AM, JMS and MN developed the protocol. AM contacted the experts and prepared the 10-item questionnaire. ADe, DM, GV, SP, STS, ADi, SK, GN, HS, SKV, SK, BU and CE formed the expert panel and contributed in the development of the framework. AM analysed the data and prepared the first draft. All authors have contributed in drafting and revising the manuscript. JMS is the guarantor of this article.

Funding The authors have not declared a specific grant for this research from any funding agency in the public, commercial or not-for-profit sectors.

Competing interests None declared.

Patient consent for publication Not applicable.

Ethics approval This study was approved by Institutional Ethics Committee, Kasturba Hospital, Manipal, India approved this study (IEC:355/2017).

Provenance and peer review Not commissioned; externally peer reviewed.

Data availability statement All data relevant to the study are included in the article or uploaded as online supplemental information.

Supplemental material This content has been supplied by the author(s). It has not been vetted by BMJ Publishing Group Limited (BMJ) and may not have been peer-reviewed. Any opinions or recommendations discussed are solely those of the author(s) and are not endorsed by BMJ. BMJ disclaims all liability and responsibility arising from any reliance placed on the content. Where the content includes any translated material, BMJ does not warrant the accuracy and reliability of the translations (including but not limited to local regulations, clinical guidelines, terminology, drug names and drug dosages), and is not responsible for any error and/or omissions arising from translation and adaptation or otherwise.

Open access This is an open access article distributed in accordance with the Creative Commons Attribution Non Commercial (CC BY-NC 4.0) license, which permits others to distribute, remix, adapt, build upon this work non-commercially, and license their derivative works on different terms, provided the original work is properly cited, appropriate credit is given, any changes made indicated, and the use is non-commercial. See: http://creativecommons.org/licenses/by-nc/4.0/.

\section{ORCID iDs}

Amreen Mahmood http://orcid.org/0000-0002-2803-3598

Coralie English http://orcid.org/0000-0001-5910-7927

\section{REFERENCES}

1 Pandian JD, Sudhan P. Stroke epidemiology and stroke care services in India. J Stroke 2013;15:128-34.

2 Winstein CJ, Stein J, Arena R, et al. Guidelines for adult stroke rehabilitation and recovery: a guideline for healthcare professionals 
from the American heart Association/American stroke association. Stroke 2016;47:e98-169.

3 Hankey G, MacLeod M, Gorelick P. Chapter 18: Rehabilitation after stroke: evidence, practice, and new directions. In: Warlow's Stroke: Practical Management. 4th edn. John Wiley \& Sons Ltd, 2019: 867-77.

4 Pandian JD, Srikanth V, Read SJ, et al. Poverty and stroke in India: a time to act. Stroke 2007;38:3063-9.

5 Craig LE, Wu O, Bernhardt J, et al. Approaches to economic evaluations of stroke rehabilitation. Int J Stroke 2014;9:88-100.

6 Legg L, Langhorne P, Outpatient Service Trialists. Rehabilitation therapy services for stroke patients living at home: systematic review of randomised trials. Lancet 2004;363:352-6.

7 Mayo NE. Stroke rehabilitation at home. Stroke 2016;47:1685-91.

8 Hillier S, Inglis-Jassiem G. Rehabilitation for community-dwelling people with stroke: home or centre based? A systematic review. Int $J$ Stroke 2010;5:178-86.

9 Flynn A, Allen NE, Dennis S, et al. Home-based prescribed exercise improves balance-related activities in people with Parkinson's disease and has benefits similar to centre-based exercise: a systematic review. J Physiother 2019;65. doi:10.1016/j. jphys.2019.08.003. [Epub ahead of print: Available from].

10 Duncan PW, Horner RD, Reker DM, et al. Adherence to postacute rehabilitation guidelines is associated with functional recovery in stroke. Stroke 2002;33:167-77.

11 Hubbard IJ, Harris D, Kilkenny MF, et al. Adherence to clinical guidelines improves patient outcomes in Australian audit of stroke rehabilitation practice. Arch Phys Med Rehabil 2012;93:965-71. doi:10.1016/j.apmr.2012.01.011

12 Gunnes M, Indredavik B, Langhammer B, et al. Associations between adherence to the physical activity and exercise program applied in the last study and functional recovery after stroke. Arch Phys Med Rehabil 2019;100:2251-9. doi:10.1016/j.apmr.2019.04.023

13 Shaughnessy M, Resnick BM, Macko RF. Testing a model of post-stroke exercise behavior. Rehabil Nurs 2006;31:15-21. doi:10.1002/j.2048-7940.2006.tb00005.x

14 Mahmood A, Solomon JM, English C, et al. Measurement of adherence to home-based exercises among community-dwelling stroke survivors in India. Physiother Res Int 2020;25:e1827.

15 Mahmood A, Nayak P, Kok G. Factors influencing adherence to home-based exercises among community-dwelling stroke survivors in India : a qualitative study. Eur. J. Physiother 2019. doi:10.1080/216 79169.2019.1635641

16 Damush TM, Plue L, Bakas T, et al. Barriers and facilitators to exercise among stroke survivors. Rehabil Nurs 2007;32:253-60. doi:10.1002/j.2048-7940.2007.tb00183.x

17 Littlewood C, Mawson S, May S, et al. Understanding the barriers and enablers to implementation of a self-managed exercise intervention: a qualitative study. Physiotherapy 2015;101:279-85. doi:10.1016/j.physio.2015.01.001

18 Clague-Baker N, Carpenter C, Robinson T, et al. A qualitative study exploring patients', with mild to moderate stroke, and their carers' perceptions of healthy lifestyles. Int J Ther Rehabil 2017;24:375-84. doi:10.12968/ijtr.2017.24.9.375

19 Nicholson S, Sniehotta FF, van Wijck F, et al. A systematic review of perceived barriers and motivators to physical activity after stroke. Int J Stroke 2013;8:357-64. doi:10.1111/j.1747-4949.2012.00880.x

20 Sabate E. Adherence to long-term therapies: evidence for action, 2003. World Health organization. Available: https://www.who.int/chp/ knowledge/publications/adherence_full_report.pdf [Accessed 14 Sept 2019].

21 Fryer CE, Luker JA, McDonnell MN, et al. Self management programmes for quality of life in people with stroke. Cochrane Database Syst Rev 2016:CD010442.

22 Jordan JL, Holden MA, Mason EE, et al. Interventions to improve adherence to exercise for chronic musculoskeletal pain in adults. Cochrane Database Syst Rev 2010;2010:CD005956.

23 Reunanen MAT, Järvikoski A, Talvitie U, et al. Individualised homebased rehabilitation after stroke in eastern Finland--the client's perspective. Health Soc Care Community 2016;24:77-85.

24 Chen M-D, Rimmer JH. Effects of exercise on quality of life in stroke survivors: a meta-analysis. Stroke 2011;42:832-7.

25 Kok G, Gottlieb NH, Peters G-JY, et al. A taxonomy of behaviour change methods: an intervention mapping approach. Health Psychol Rev 2016:10:297-312.

26 Mahmood A, Nayak P, English C, et al. Adherence to home exercises and rehabilitation (adhere) after stroke in low-to-middleincome countries: a randomized controlled trial. Top Stroke Rehabil $2021 ; 28: 1-11$
27 Pill J. The Delphi method: substance, context, a critique and an annotated bibliography. Socioecon Plann Sci 1971;5:57-71.

28 Direito A, Walsh D, Hinbarji M, et al. Using the intervention mapping and behavioral intervention technology frameworks: development of an mHealth intervention for physical activity and sedentary behavior change. Health Educ Behav 2018;45:331-48. doi:10.1177/1090198117742438

29 Peek K, Carey M, Sanson-Fisher R, et al. Aiding patient adherence to physiotherapist-prescribed self-management strategies: an evidence-based behavioural model in practice. Phys Ther Rev 2016;21:124-30. doi:10.1080/10833196.2016.1226537

30 Kwasnicka D, Dombrowski SU, White M, et al. Theoretical explanations for maintenance of behaviour change: a systematic review of behaviour theories. Health Psychol Rev 2016;10:277-96.

31 Picorelli AMA, Pereira LSM, Pereira DS, et al. Adherence to exercise programs for older people is influenced by program characteristics and personal factors: a systematic review. $J$ Physiother 2014;60:151-6.

32 Meade LB, Bearne LM, Sweeney LH, et al. Behaviour change techniques associated with adherence to prescribed exercise in patients with persistent musculoskeletal pain: systematic review. $\mathrm{Br} \mathrm{J}$ Health Psychol 2019;24:10-30.

33 DiMatteo MR, Haskard-Zolnierek KB, Martin LR. Improving patient adherence: a three-factor model to guide practice. Health Psychol Rev 2012;6:74-91.

34 Picha KJ, Howell DM. A model to increase rehabilitation adherence to home exercise programmes in patients with varying levels of selfefficacy. Musculoskeletal Care 2018;16:233-7.

35 Hsieh H-F, Shannon SE. Three approaches to qualitative content analysis. Qual Health Res 2005;15:1277-88. doi:10.1177/1049732305276687

36 Michie S, Van SMM, West R. The behaviour change wheel : A new method for characterising and designing behaviour change interventions The behaviour change wheel : A new method for characterising and designing behaviour change interventions. Implement. Sci 2011:6:42. doi:10.1186/1748-5908-6-42

37 Jünger S, Payne SA, Brine J, et al. Guidance on conducting and reporting Delphi studies (CREDES) in palliative care: recommendations based on a methodological systematic review. Palliat Med 2017;31:684-706.

38 Bartholomew LK, Parcel GS, Kok G. Intervention mapping: a process for developing theory- and evidence-based health education programs. Health Educ Behav 1998;25:545-63.

39 Kok G, Gottlieb NH, Commers M, et al. The ecological approach in health promotion programs: a decade later. Am J Health Promot 2008;22:437-42. doi:10.4278/ajhp.22.6.437

40 McGrane N, Galvin R, Cusack T, et al. Addition of motivational interventions to exercise and traditional physiotherapy: a review and meta-analysis. Physiotherapy 2015;101:1-12. doi:10.1016/j. physio.2014.04.009

41 Peek K, Sanson-Fisher R, Mackenzie L, et al. Interventions to aid patient adherence to physiotherapist prescribed self-management strategies: a systematic review. Physiotherapy 2016;102:127-35. doi:10.1016/j.physio.2015.10.003

42 Oesch P, Kool J, Fernandez-Luque L, et al. Exergames versus selfregulated exercises with instruction leaflets to improve adherence during geriatric rehabilitation: a randomized controlled trial. BMC Geriatr 2017; 17:77.

43 Okezue OC, Nwafor GC, Ezeukwu OA, et al. Adherence to home exercise programmes and its associated factors among patients receiving physiotherapy. Clinhp 2019;9:7-14. doi:10.29102/ clinhp. 19003

44 Eynon M, Foad J, Downey J, et al. Assessing the psychosocial factors associated with adherence to exercise referral schemes: a systematic review. Scand J Med Sci Sports 2019;29:1-13.

45 Yao M, Chen J, Jing J, Tan X, et al. Defining the rehabilitation adherence curve and adherence phases of stroke patients: an observational study. Patient Prefer Adherence 2017;11:1435-41.

46 Dimatteo MR, Haskard KB, Williams SL. And patient adherence: a meta-analysis. Med. Care 2007;45:521-8.

47 Jaracz K, Grabowska-Fudala B, Kozubski W. Caregiver burden after stroke: towards a structural model. Neurol Neurochir Pol 2012:46:224-32.

48 Kamalakannan S, Gudlavalleti Venkata M, Prost A, et al. Rehabilitation needs of stroke survivors after discharge from hospital in India. Arch Phys Med Rehabil 2016;97:1526-32. doi:10.1016/j. apmr.2016.02.008 